\title{
Influence of alloying and secondary annealing on anneal hardening effect at sintered copper alloys
}

\author{
SVETLANA NESTOROVIC \\ Technical Faculty Bor, University of Belgrade, Bor, Yugoslavia \\ MS received 11 February 2004; revised 29 October 2004
}

\begin{abstract}
This paper reports results of investigation carried out on sintered copper alloys $(\mathrm{Cu}, 8$ at\%; $\mathrm{Zn}$, $\mathrm{Ni}, \mathrm{Al}$ and $\mathrm{Cu}-\mathrm{Au}$ with 4 at\% $\mathrm{Au})$. The alloys were subjected to cold rolling $(30,50$ and $70 \%)$ and annealed isochronally up to recrystallization temperature. Changes in hardness and electrical conductivity were followed in order to investigate the anneal hardening effect. This effect was observed after secondary annealing also. Au and $\mathrm{Al}$ have been found to be more effective in inducing anneal hardening effect.
\end{abstract}

Keywords. Alloying; secondary annealing; anneal hardening effect; copper alloys.

\section{Introduction}

Copper has excellent conductivity, but has poor resistance to softening and low strength at moderate temperatures. This presents a considerable problem to engineers and designers of electrical equipment (Kothari 1984). The last few years have seen a major effort devoted to the exploration of copper based alloys in the search for improvements in properties such as strength, conductivity, and stress retention at high temperatures (Vlasjuk 1989; Morris 1999; Salkova and Pisarenko 1991). Copper is conventionally hardened by solution and/or precipitation hardening and dispersion hardening. One of the mechanisms employed to improve the mechanical properties of single-phase copper alloys is anneal hardening whereby, considerable strengthening is attained when alloys in cold rolled state are annealed at $423-573 \mathrm{~K}$. This effect was investigated mainly on cast copper based alloys (Bader et al 1976; Vitek and Warlimont 1979).

Our preliminary investigations on $I / M$ and $P / M$ copper alloys show anneal hardening effect in the temperature range $423-573 \mathrm{~K}$, when hardness and strength increase with increasing substitutional solute concentration (Nestorovic and Markovic 1997, 1999; Nestorovic and Tančić 2001; Nestorovic et al 2002). The amount of strengthening increases with increasing degree of prior cold work. DTA analysis showed the exothermic heat effect in the temperature range where the anneal hardening effect is observed (Nestorovic et al 2003). No work has been done on the anneal hardening effect in sintered copper alloys. The present study gives results of investigation on the influence of alloying elements: $\mathrm{Zn}, \mathrm{Ni}, \mathrm{Al}, \mathrm{Au}$ and the instance of secondary annealing on the anneal hardening effect in copper based sintered alloys.

(snestorovic@tf.bor.ac.yu)

\section{Experimental}

Various copper based alloys were prepared using electrolytic copper powder and powders with 8 at $\%$ of alloying element: Ni, Zn, Al and 4 at\% Au. Specimens with dimension, $12 \mathrm{~mm}$ wide, $30 \mathrm{~mm}$ long and $6 \mathrm{~mm}$ thick, were pressed employing a pressure of $300 \mathrm{MPa}$ in a hydraulic press. The pressed compacts were sintered isothermally at $1123 \mathrm{~K}$ for $1 \mathrm{~h}$, in a graphite furnace under an atmosphere of nitrogen. After sintering, hardness and electrical conductivity were measured on the specimens and then cold rolling was carried out with different deformation degrees $(30,50,70 \%)$. The cold rolled specimens were isochronally annealed at $30 \mathrm{~min}$ intervals in the temperature range $423-773 \mathrm{~K}$ and the Vickers hardness and electrical conductivity were measured. The samples of recrystallized alloys were then subjected to cold rolling again with deformation of 45 and $60 \%$. After measuring the hardness and electrical conductivity they were annealed again in the temperature range $423-773 \mathrm{~K}$ in order to investigate the anneal hardening effect.

\section{Results and discussion}

\subsection{Cold rolled sintered samples}

Figure 1 shows the variation of hardness of copper and its alloys on degree of deformation during cold rolling. The hardness of the sintered samples increases with deformation degree due to strain hardening. Higher hardness values were obtained for alloys than for pure copper. Maximum value of hardness was about $150 \mathrm{Hv}$ for $70 \%$ deformation i.e. maximum of work hardening was attained in the alloy, $\mathrm{Cu}-\mathrm{Ni}$.

Figure 2 shows the dependence of electrical conductivity on the amount of cold rolling of sintered samples. It can 
be seen that the electrical conductivity slowly increases with deformation degree. This is a result of two opposing effects. The decrease in porosity of sintered samples during cold rolling results in an increase in the electrical conductivity. However, cold-working results in a decrease in the electrical conductivity. It appears that the first effect is larger than the second, and the electrical conductivity increases as a result.

Also, figure 2 shows that the electrical conductivity of sintered copper is higher than in sintered alloys and therefore, the contents of the alloying elements must be kept to minimum (say to $3 \%$ ), because alloying elements decrease the electrical conductivity. $\mathrm{Ni}$ and $\mathrm{Al}$ have the most remarkable influence on the decreased electrical conductivity of copper.

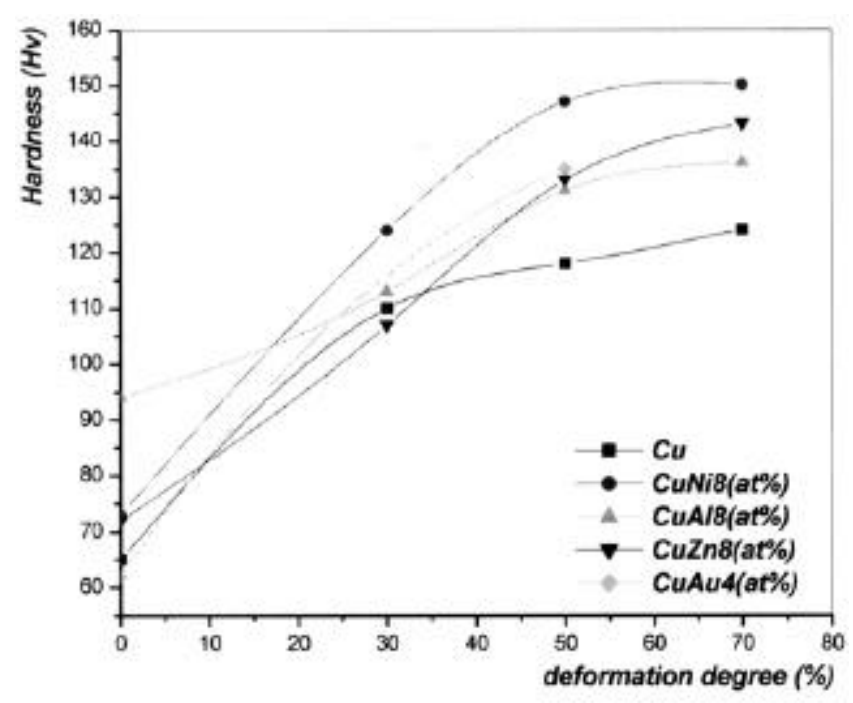

Figure 1. Dependence of hardness of cold rolled sintered samples on degree of deformation.

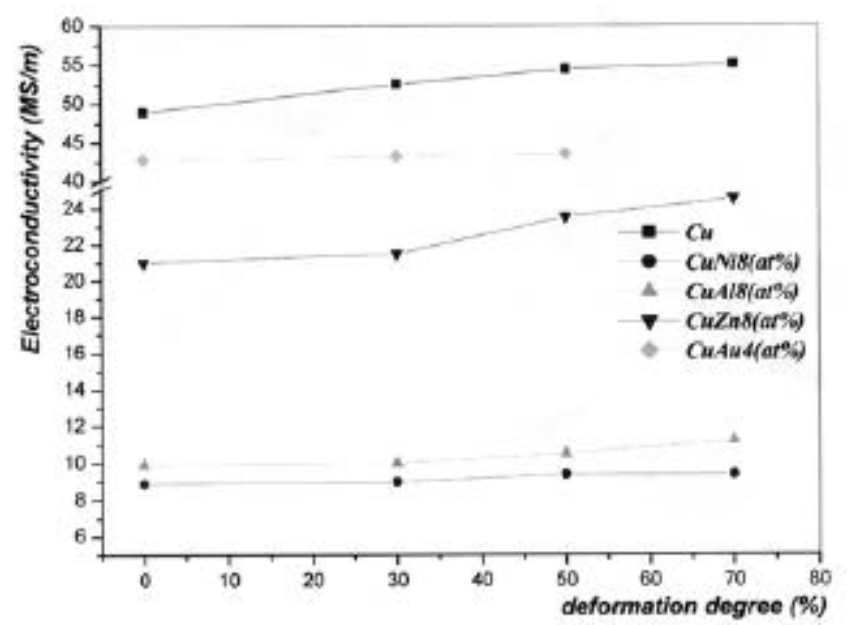

Figure 2. Dependence of electrical conductivity of cold rolled sintered samples on degree of deformation.

\subsection{Annealed cold rolled sintered samples}

3.2a Primary annealed sintered samples: Figure 3 shows the dependence of hardness on the annealing temperature for sintered and 50\% cold rolled copper and alloys. It can be seen that the hardness of pure copper decreases above $493 \mathrm{~K}$, i.e. recrystallization temperature of pure copper is above $493 \mathrm{~K}$, but for the alloys it is about $723 \mathrm{~K}$. It can also be seen that in the temperature range 423-623 K, the hardness increases for all the alloys. The increase is about $12 \mathrm{Hv}$ at $493 \mathrm{~K}$ for $\mathrm{Cu}-\mathrm{Ni}$, about $30 \mathrm{Hv}$ at $533 \mathrm{~K}$ for $\mathrm{Cu}-\mathrm{Al}$, about $6 \mathrm{Hv}$ for $\mathrm{Cu}-\mathrm{Zn}$ at the same temperature and about $20 \mathrm{Hv}$ for $\mathrm{Cu}-\mathrm{Au}$ at $573 \mathrm{~K}$. These data demonstrate clearly that all the alloy systems investigated exhibited the anneal hardening effect. This effect was earlier investigated mainly in cast copper-based alloys containing $\mathrm{Al}, \mathrm{Ni}, \mathrm{Au}, \mathrm{Ga}, \mathrm{Pa}, \mathrm{Rh}$ and $\mathrm{Zn}$ (Vitek and Warlimont 1979). The reason advanced for this hardening phenomenon was solute segregation to dislocations, analogous to the formation of Cottrell atmospheres in interstitial solid solutions.

Figure 4 shows the change of electrical conductivity of cold rolled sintered copper and copper alloys with annealing temperature. The electrical conductivity slowly increases with annealing temperature due to recovery and recrystallization. Electrical conductivity of the alloys also increases in the temperature range of anneal hardening effect. Bader et al (1976) obtained similar results by electrical conductivity measurements.

3.2b Secondary annealed sintered samples: After primary annealing, the recrystallized samples were again subjected to cold rolling with different degrees of deformation $(45,50,60 \%)$ and then secondary annealed.

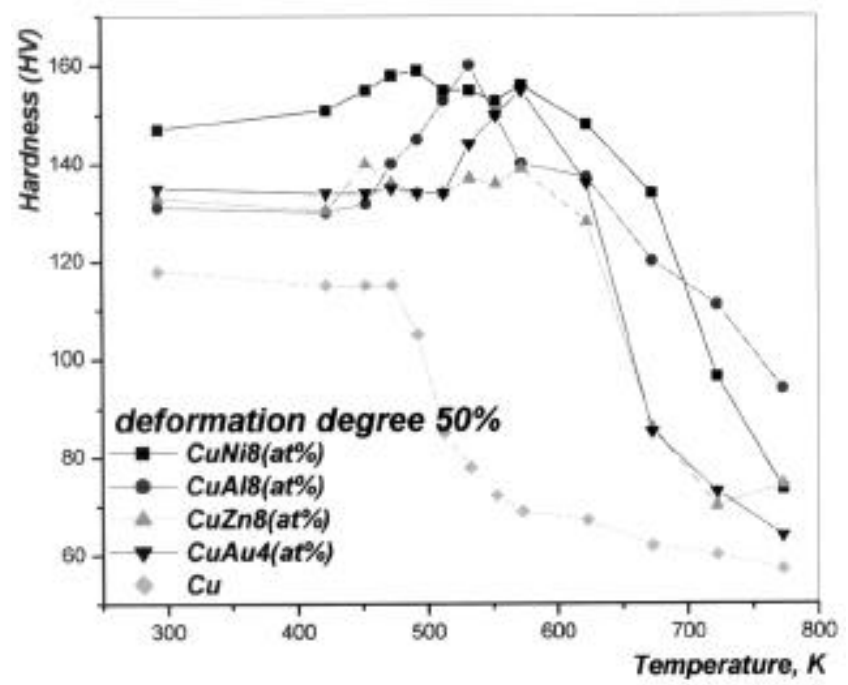

Figure 3. Variation of hardness of cold rolled (50\%) sintered copper and alloys with annealing temperature. 


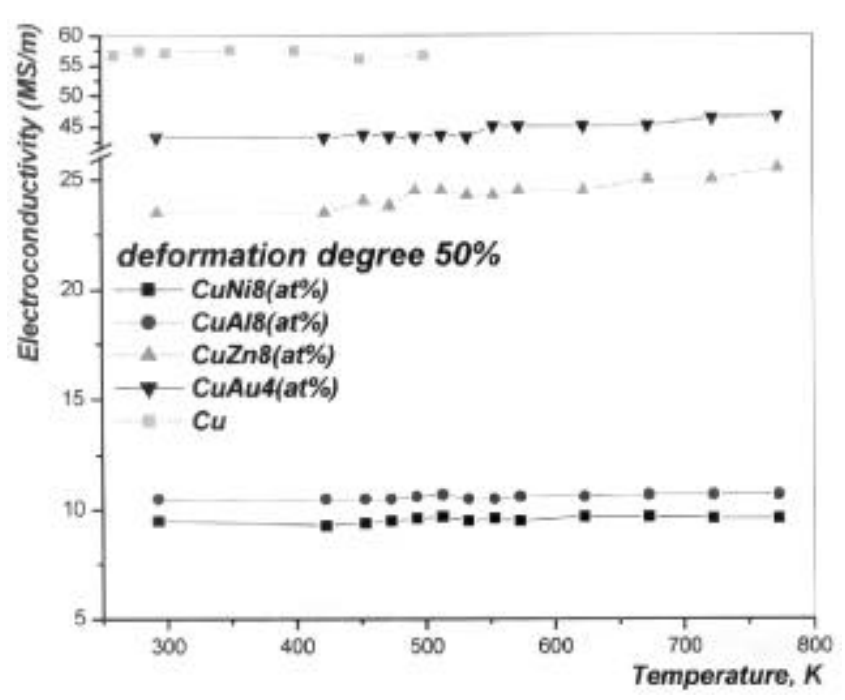

Figure 4. Variation of electrical conductivity of cold rolled copper and alloys with annealing temperature.

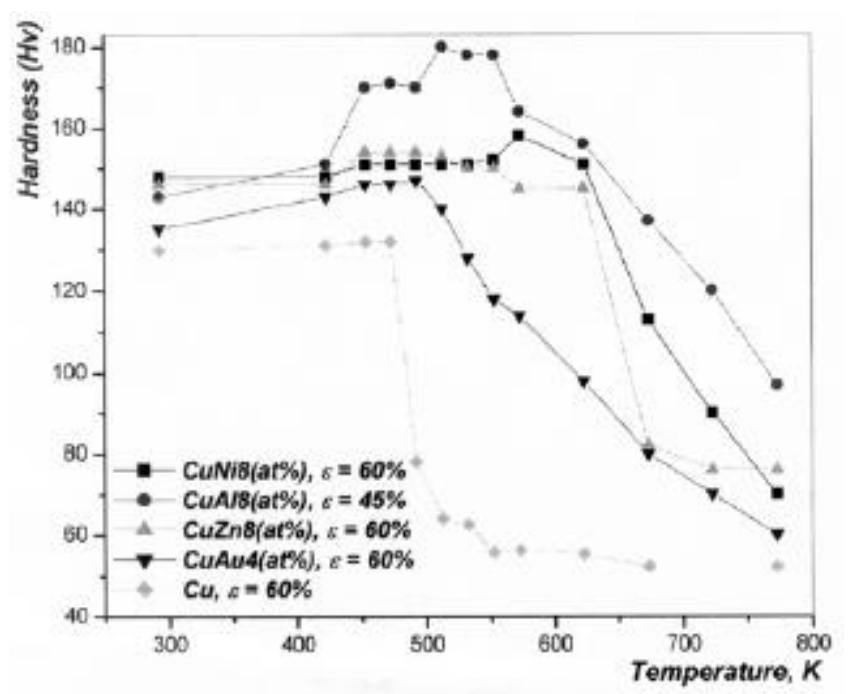

Figure 5. Variation of hardness of secondary cold rolled samples with secondary annealing temperature.

Figure 5 shows the dependence of hardness on secondary annealing temperature. It can be seen that the recrystallization temperature for copper for deformation degree of $60 \%$ is above $473 \mathrm{~K}$, but for the alloys it is above $673 \mathrm{~K}$. It can be seen that the hardness exhibits a peak in the temperature range $423-623 \mathrm{~K}$ in all the alloys i.e. anneal hardening effect is again observed. As in the first case (figure 3), the maximum hardness value increase is seen in $\mathrm{Cu}-\mathrm{Al}$ alloy (about $37 \mathrm{Hv}$ ), at a temperature of $513 \mathrm{~K}$. Anneal hardening effect is more evident after primary annealing than after secondary annealing in all alloys (figures 3 and 5).

\section{Conclusions}

(I) Anneal hardening effect was observed in the cold rolled sintered copper alloys: $\mathrm{CuNi}, \mathrm{CuZn}, \mathrm{CuAl}$ and $\mathrm{CuAu}$, in the temperature range $423-623 \mathrm{~K}$, and is accompanied by an increase in hardness and electrical conductivity.

(II) The anneal hardening effect is more noticeable in the temperature range $473-573 \mathrm{~K}$, i.e. under recrystallization conditions.

(III) The maximum value of hardness due to anneal hardening effect was attained in $\mathrm{Cu}-\mathrm{Au}$ and $\mathrm{Cu}-\mathrm{Al}$ alloy systems.

(IV) The alloying elements, Ni, $\mathrm{Zn}, \mathrm{Al}$ and $\mathrm{Au}$ were found to have a pronounced effect on the recrystallization temperature of cold rolled sintered copper.

(V) The anneal hardening effect was observed after primary and again after secondary annealing of cold rolled sintered copper based alloys.

(VI) $\mathrm{Ni}$ and $\mathrm{Al}$ have a pronounced effect on the decrease in the electrical conductivity of copper.

\section{References}

Bader M, Eldis G T and Warlimont H 1976 Metall. Trans. A7 249

Kothari N C 1984 Mod. Dev. Powder Metall. (Toronto) 16361

Morris D G 1999 Powder Metall. 4220

Nestorović S and Marković D 1997 Metallurgia 3297

Nestorović S and Marković D 1999 Mater. Trans. JIM 40222

Nestorović S and Tančić D 2001 European congress and exhibition on powder metallurgy, Nice, France, in EPMA Proc. (Shrewsbury, UK) Vol. 2, pp 158-164

Nestorović S, Milićević B and Marković D 2002 Sci. Sinter. 34 169

Nestorović S, Marković D and Ivanic Lj 2003 Bull. Mater. Sci. 26601

Salkova S and Pisarenko T V 1991 Poroškovaja Metallurgija 988 Vitek J M and Warlimont H 1979 Metall. Trans. A10 1889

Vlasjuk R Z 1989 Poroš kovaja Metallurgija 443 